\title{
The Use of Indicators for Unobservable Product Qualities: Inferences Based on Consumer Sorting
}

\author{
Matthew G. Nagler ${ }^{1}$, Fredi Kronenberg ${ }^{2}$, Edward J. Kennelly ${ }^{3}$, Bei Jiang ${ }^{4} \&$ Chunhui $\mathrm{Ma}^{5}$ \\ ${ }^{1}$ Department of Economics and Business, The City College of New York, New York, NY, USA \\ ${ }^{2}$ Department of Anesthesia, Stanford University School of Medicine, Palo Alto, CA, USA \\ ${ }^{3}$ Department of Biological Sciences, Lehman College and The Graduate Center, City University of New York, \\ Bronx, NY, USA \\ ${ }^{4}$ College of Pharmacy, Dali University, Dali, Yunnan, China \\ ${ }^{5}$ Department of Biological Sciences, Lehman College, Bronx, NY, USA \\ Correspondence: Matthew G. Nagler, Department of Economics and Business, The City College of New York, \\ NAC 4/121, 160 Convent Avenue, New York, NY 10031, USA. Tel: 1-212-650-6205. E-mail: \\ mnagler@ccny.cuny.edu
}

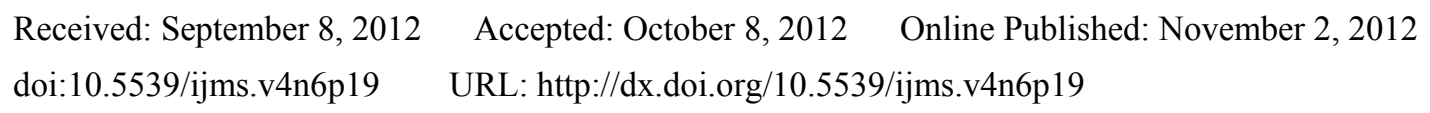

\begin{abstract}
We propose a method for measuring the conjectural errors that inexpert consumers make relative to experts in using observable product characteristics as surrogate indicators of a valued unobservable characteristic. Observations on the unobservable characteristic, available to the researcher but not consumers, are used to divide the data into high- and low-quality subsamples. Separate hedonic estimation on the subsamples enables measurement of the relative valuations and conjectures of experts and non-experts with respect to indicators under the assumption that consumers sort across quality grades based on their appraisal expertise. The method is demonstrated using a small sample of SKU-level data on the dietary supplement black cohosh. Our exploratory findings on this sample suggest that, relative to experts, inexpert consumers underestimate the value of most observable characteristics as indicators of black cohosh chemical authenticity; however they overweight therapeutic claims on the product label as a negative indicator of authenticity.
\end{abstract}

Keywords: consumer behavior, expertise, surrogate indicators, missing information, credence goods, hedonic analysis

\section{Introduction}

Prices indicate the product characteristics that consumers value, but they do not tell us why consumers value them. While in some cases consumers might value a characteristic intrinsically, in other cases characteristics are valued as a signal, or surrogate indicator, of the level of some quality that is not directly observable. For example, a knowledgeable owner of a porcelain vase may find its shape and painted decoration aesthetically pleasing; meanwhile, she may value the vase's thickness as an indicator of its authenticity as an artifact of the Ming Dynasty, rather than, say, because it makes the vase more durable or beautiful (Brook, 1998, pp. 225-226). Traditional hedonic analysis, which deals in the valuation of observable qualities, would tell us only that consumers value thickness in a vase. Moreover, additional questions relevant to marketing arise in the context of unobservable qualities that the standard hedonic approach does not answer. Do consumers accord full value to a characteristic as an indicator of an unobserved quality, or do they undervalue it as such because they are unaware or tentative with respect to the characteristic's indicator capabilities? Do consumers, on the other hand, accord too much value to the characteristic as an indicator and rely too heavily on it? Do different consumers make different conjectures in this regard? If so, how does one identify the different consumers? To answer these questions, it is necessary, inter alia, to measure the quality unobservable to consumers - in the Ming vase example, authenticity - something that is not an element of traditional hedonic analysis.

This paper demonstrates a method for extracting information on consumers' use of observable product characteristics as surrogate indicators. It makes use of data measuring authenticity (i.e., whether the product contains the key ingredients claimed on the label) for a sample of brands of black cohosh, a dietary supplement 
believed to help with menopause symptoms. Black cohosh is properly characterized as a credence good, or product for which key quality-related characteristics (such as botanical authenticity) are not observable even after purchase and use (Darby \& Karni, 1973; Dulleck \& Kerschbamer, 2006). We obtain data on authenticity in the laboratory through a standard analytical method called high-performance liquid chromatography. Thus we observe a critical quality-related product characteristic that consumers have not. While this may appear at first blush to present a unique situation, data on consumer-unobservable characteristics are similarly available to researchers in many typical marketing contexts. As experts on their categories, product manufacturers often have superior information on the quality of competing products relative to consumers. Sophisticated quality measurement techniques, such as those used by Consumer Reports and other independent testers, while infeasible for most consumers, may be feasible for researchers.

Two problems complicate the process of empirical inference in this context. The first is, as suggested by the above discussion, that consumers are not generally expert appraisers of key unobservable qualities. Consumers may be unaware of the need to appraise a certain unobservable quality, or unaware that information at their disposal from observable characteristics could provide insight into it. (Note 1) Or, they may be aware that an observable characteristic can help in appraisal of an unobservable quality, but they may not know in what way or to what extent. If this last holds true, then the econometric relationship between the indicators and the unobserved quality is not the one consumers conjecture, hence that relationship does not provide an accurate basis for determining how the indicator variables are being valued by the market.

We classify inexpert appraisal using surrogate indicators into three cases. A consumer might overshoot, overestimating the power of the surrogate indicator to predict the unobservable characteristic. Or she might undershoot, underestimating its power of prediction. Or she might entertain a fallacy, reversing in her prediction the true sign of the relationship between surrogate indicator and unobservable characteristic. Expert appraisal is nested in this structure as a boundary sub-case between "overshoot" and "undershoot," while unawareness is a boundary sub-case between "undershoot" and "fallacy."

The second problem is that consumers are not all the same. Some are more expert than others. This means hedonic analysis, which relies on the assumption that consumers express homogenous preferences, is inappropriate when applied indiscriminately to the mass of consumers. (Note 2) Moreover, the problem of inferring consumers' conjectures becomes complex, since those conjectures vary across consumers.

We extract information about different consumers' use of surrogate indicators by inferring consumers' expertise levels from their choices. Consumers with greater appraisal expertise are better at discerning quality, and so sort disproportionately to higher quality products. This enables the researcher to measure the surrogate indicator valuations and conjectural errors of inexpert consumers relative to experts by separately performing hedonic analysis on high- and low-quality product pools. Importantly, this process constitutes a justifiable use of the hedonic model assuming consumers' effective preferences within quality pool are sufficiently homogeneous. We demonstrate the method using separate estimation on authentic and non-authentic black cohosh subsamples.

The rest of the paper is organized as follows. Section 2 provides a brief review of relevant literatures. Section 3 lays out a model of unobservable characteristics and surrogate indicators, examines the empirical problem posed by inexpert consumer appraisal, and considers how a hedonic approach predicated on consumer sorting addresses the problem. In Section 4, we apply our approach to the market for black cohosh. Section 5 concludes by discussing managerial implications, limitations of the current study, and possible objectives for future research.

\section{Literature Review}

The marketing literature on expertise provides a useful background on this decision-maker trait and its relevance. Alba \& Hutchinson (1987) define five dimensions of consumer expertise that are influenced by product familiarity. Mitchell \& Dacin (1996) offer experimental evidence of the effect of expertise on consumers' performance at predictive tasks. They also provide an excellent review (p. 219) of the psychological literature relating expertise to performance levels in various cognitive functional areas. Additional evidence of the relationship of expertise to consumer performance is offered by Chiou (2003); Maheswaran (1994); and Maheswaran, Sternthal, \& Gürhan (1996).

The idea that consumers sort across quality grades based on differences in expertise or ability is not new.A number of theoretical analyses have considered market outcomes in situations in which some consumers are inattentive, unskilled, or otherwise experience higher costs to evaluating market information than others (Armstrong \& Chen, 2009; Gabaix \& Laibson, 2006; Nagler, 1993; Salop \& Stiglitz, 1977). One consistent finding across this literature is that people with different abilities select different products (or, more generally, 
product choice strategies), such that more skilled, less cost-encumbered individuals get better deals than those less skilled and more cost-encumbered. The present paper's innovation is to advance an empirical methodology that uses sorting as a tool to extract information relevant to managerial decision-making. One may apply the methods developed in this study to create targeted pricing, product and promotion strategies based on consumer expertise levels. The methods may also be used to develop and evaluate public policies, particularly policies related to marketing practices and consumer outcomes (see Section 5).

A number of researchers have studied the processes by which consumers infer product attributes for which information is missing (e.g., Broniarczyk \& Alba, 1994; Dick, Chakravarti, \& Biehal, 1990; Johnson \& Levin, 1985; Pinson, 1986; Ross \& Creyer, 1992; Sanbonmatsu, Kardes, \& Sansone, 1991; Sanbonmatsu, Kardes, Houghton, Ho, \& Posavac, 2003). A literature specifically devoted indicators of product quality focuses largely on how different surrogate indicators, such as country-of-origin and perceived difficulty of manufacture, influence consumers' perceptions of unobservable quality (e.g., Jo, 2005; Johnson \& Folkes, 2007; Quester, Dzever, \& Chetty, 2000; West, Larue, Gendron, \& Scott, 2002).Much of the research emphasis has been on the role of price as an indicator of quality; analyses have included experimental studies (e.g., Brucks, Zeithaml, \& Naylor, 2000; West et al., 2002) and some meta-analytic reviews (Rao \& Monroe, 1989; Völckner \& Hofmann, 2007).By and large, the studies in these categories are descriptive: none provides a methodology for using data on consumer-unobservable qualities as a tool for making inferences about consumers' valuations and quality judgments.

Another strand of work, related to the literature on the role of indicators, looks at the accuracy of consumer perceptions. In a set of analyses involving both durable and non-durable goods, Burton \& Lichtenstein (1989, 1990) considered how consumers' perceptions of the price-quality relationship contrast with actual price-quality. Mason, Burton, \& Roach (2001) examined the determinants of consumers' accuracy at judging brand performance on various attributes. One thing these studies have in common is that they ascertain consumer accuracy using as benchmarks for "objective" quality measures that are publicly available to consumers - for example, ratings in Consumer Reports. The present paper is unique in that its measure of objective quality is one that consumers could not possibly have observed themselves; thus we eliminate the possibility that consumers may have improved their accuracy by "peeking" at the objective measures.

\section{Conceptual Framework and Approach}

\subsection{Unobservable Product Qualities}

The standard hedonic approach posits a continuum of differentiated products, perfect competition, complete information, and consumers with homogeneous preferences who value a product as a bundle of characteristics (Rosen, 1974; Kristensen, 1984). Let us stipulate to these assumptions for the moment, and specifically let us consider a differentiated product space consisting of $K$ observable characteristics, $X_{k}, k=1, \ldots, K$, and one unobservable characteristic, $z$. Thus the utility the representative consumer obtains from consuming the product is given by

$$
U=U\left(X_{1}, \ldots, X_{K}, z\right)
$$

Maximization of (1) subject to a budget constraint produces a hedonic price function, for brand $i$,

$$
p_{i}=f\left(X_{1 i}, \ldots, X_{K i}, z\right)
$$

where $X_{k}$ is the value of the $k$ th characteristic for brand $i$ and $p_{i}$ the price level for $i$ (Huang and Lin 2007). The corresponding hedonic log regression equation specifies

$$
P_{i}=\alpha+\beta_{1} X_{1 i}+\ldots+\beta_{K} X_{K i}+\xi_{i}
$$

where $P_{i} \equiv \log p_{i}$ and $\xi$ is a stochastic disturbance term. Note that $z$ does not enter this regression because it is not observable. Estimation of the equation in (3) allows measurement of the extent to which the consumer values increments in each of the observable variables, that is, $\beta_{k}=\partial P / \partial X_{k}$. But, as discussed in the introduction, it does not provide information on the extent to which observables are valued as indicators of $z$. Nor does one get any sense as to how much the consumer values increments in $z$.

In general, the value of each observable characteristic $X_{k}$ provides information about the value of $z$, following from some functional relationship

$$
z=z\left(X_{1}, \ldots, X_{K}\right)
$$

Assuming $\partial z / \partial X_{k}$ is nonzero, $X_{k}$ is said to be a surrogate indicator of $z$. If $\partial z / \partial X_{k}>0$, then we say that $X_{k}$ is a positive indicator of $z$. If $\partial z / \partial X_{k}<0, X_{k}$ is a negative indicator of $z$. We may therefore decompose the partial derivative of $P$ with respect to the $X_{k}$ in (3) as 


$$
\partial P / \partial X_{k}=\partial P /\left.\partial X_{k}\right|_{D}+\partial P / \partial z \cdot \partial z / \partial X_{k}
$$

That is, the effect of each observable characteristic on the log price of the product is equal to the sum of its direct effect as a quality with intrinsic value to the consumer and its indirect effect as a surrogate indicator to the consumer of the valued unobservable characteristic (Note 3).

Now suppose we are able to privately observe $z$, so that $z$ may be included along with the observable variables. Then (3) becomes

$$
P_{i}=\alpha_{D}+\lambda z_{i}+\beta_{1 D} X_{1 i}+\ldots+\beta_{K D} X_{K i}+\eta_{i}
$$

where $\eta$ is the stochastic disturbance term for the augmented equation. Also, approximating (4) with a linear relationship, we may write a regression equation that determines the value of $z$,

$$
z_{i}=a+b_{1} X_{1 i}+\ldots+b_{K} X_{K i}+\varepsilon_{i}
$$

where $\varepsilon$ is a stochastic disturbance. In (6), the effect of the $X_{k}$ on $\log$ price through $z$ is controlled for, so a decompgsition has been effected. The coefficients on the $X_{k}$ represent the direct effect of the $X_{k}$ on log price, $\partial P\left|\partial X_{k}\right|_{D}$, purged of the effect that the $X_{k}$ have as indicators of the value of $z$. Since the coefficient on $z$ is $\partial P / \partial z$, it appears that by estimating (3) and (6), we would obtain each component in (5).

\subsection{Inexpert Appraisal}

The above estimation procedure makes a critical assumption that all consumers incorporate the full $\partial z / \partial X_{k}$ in their valuation of the $X_{k}$. This is because including $z$ in (6) controls for the $\partial z / \partial X_{k}$ based on the actual empirical relationship of $z$ to the $X_{k}$. Thus it assumes that consumers are aware of all the information each observable characteristic provides about the value of $z$. This is true if consumers are expert appraisers of $z$, but it is not true if they are not.

Let us continue to maintain the assumption of a single representative consumer, but allow that the consumer might not be an expert appraiser of $z$. In light of this, it is necessary to be more precise about what we mean by $\partial z / \partial X_{k}$. Let us define $\partial z\left|\partial X_{k}\right|_{T}$ as the total information content that $X_{k}$ provides on $z$, which in turn may be thought of as the sum of two components: $\partial z /\left.\partial X_{k}\right|_{A}$, the component the consumer is aware of or presumes in her appraisal of $z$; and $\partial z /\left.\partial X_{k}\right|_{U}$, the component the consumer is unaware of (i.e., the gap between the actual $\partial z\left|\partial X_{k}\right|_{T}$ and what the consumer presumes). With this newly defined structure, the decomposition in (5) is re-written as

$$
\partial P / \partial X_{k}=\partial P /\left.\partial X_{k}\right|_{D}+\partial P / \partial z \cdot \partial z /\left.\partial X_{k}\right|_{A}
$$

reflecting that the surrogate indicator influence of the $X_{k}$ on log prices occurs only through that portion of the $X_{k}$ 's explaining power that the consumer presumes.

Now it may be seen that estimation of (6) actually yields $\partial P /\left.\partial X_{k}\right|_{D}-\partial P / \partial z \cdot \partial z /\left.\partial X_{k}\right|_{U}$ as the coefficients on the $X_{k}$, not the $\partial P /\left.\partial X_{k}\right|_{D}$; the latter are unrecoverable without knowing the extent and nature of the consumer's inexpert use of each surrogate indicator $X_{k}$. Put another way, estimation of (6) provides biased estimates of the $\partial P /\left.\partial X_{k}\right|_{D}$, where the bias is given by $-\partial P / \partial z \cdot \partial z /\left.\partial X_{k}\right|_{U}$. The sign of the bias for each $X_{k}$ depends on three things: whether the unobservable characteristic $z$ is valued positively or negatively by the market (i.e., the sign of $\partial P / \partial z$ ), whether $X_{k}$ is a positive or negative surrogate indicator of $z$ (i.e., the sign of $\partial z /\left.\partial X_{k}\right|_{T}$ ), and the nature of consumers' inexpertise in using $X_{k}$ to appraise $z$ (i.e., the relationship of $\partial z /\left.\partial X_{k}\right|_{A}$ to $\left.\partial z /\left.\partial X_{k}\right|_{T}\right)$.

Delving into this last item in greater detail, let us assume that consumers exhibit a consistent form of inexpert appraisal for each $X_{k}$, that is, the relationship of $\partial z /\left.\partial X_{k}\right|_{A}$ to $\partial z /\left.\partial X_{k}\right|_{T}$ does not vary for a given $k$. We classify this relationship into three mutually exclusive and collectively exhaustive cases based on the value of

$$
\mu_{k} \equiv\left(\left.\frac{\partial z}{\partial x_{k}}\right|_{A}\right) /\left(\left.\frac{\partial z}{\partial x_{k}}\right|_{T}\right) \text {. }
$$

First, suppose $\mu_{k}>1$. This implies consumers sign the relationship between $X_{k}$ and $z$ correctly but perceiye that $X_{k}$ moves $z$ more than it actually does. In this case, consumers overshoot. Second, suppose $\mu_{k} \in(0,1)$. This implies consumers sign the relationship between $X_{k}$ and $z$ correctly but perceive that $X_{k}$ moves $z$ less than it actually does. In this case, consumers undershoot. Third, suppose $\mu_{k}<0$. This implies consumers sign the relationship between $X_{k}$ and $z$ incorrectly - that is, they perceive $z$ rises with $X_{k}$ when it actually falls, or falls with $X_{k}$ when it actually rises. In this case, consumers are said to entertain a fallacy about the $X_{k}$. 
Complete unawareness of a surrogate indicator would be represented by the borderline value $\mu_{k}=0$, while for expert appraisers $\mu_{k}=1$.

Table 1 summarizes the researcher's potential bias outcomes based on this classification. For example, for a positively valued unobservable characteristic and positive surrogate indicator, the estimate of $\partial P\left|\partial X_{k}\right|_{D}$ is positively biased when consumers overshoot. Intuitively, this is because consumers assign more surrogate indicator value to the variable then merited by its actual empirical relationship to the unobservable characteristic; so their intrinsic valuation of the variable, as a component of overall valuation, is overestimated when the estimation considers the actual empirical relationship instead of the perceived one. Note that while we may speak of the biases in estimation conditional on each consumer conjecture, we normally are able to measure neither the estimation bias nor the conjecture.

Table 1. Researcher's bias in estimating $\partial \mathrm{P} /\left.\partial \mathrm{X}_{\mathrm{k}}\right|_{\mathrm{D}}$

\begin{tabular}{lll}
\hline & $\mu_{\mathrm{k}}<1$ & $\mu_{\mathrm{k}}>1$ \\
\hline $\begin{array}{l}\mathrm{P} / \partial \mathrm{z}, \partial \mathrm{z} /\left.\partial \mathrm{X}_{\mathrm{k}}\right|_{\mathrm{T}} \\
\text { same sign }\end{array}$ & Negative & Positive \\
$\begin{array}{l}\partial \mathrm{P} / \partial \mathrm{z}, \partial \mathrm{z} /\left.\partial \mathrm{X}_{\mathrm{k}}\right|_{\mathrm{T}} \\
\text { opposite sign }\end{array}$ & Positive & Negative \\
\hline
\end{tabular}

The empirical conundrum created by consumers' inexpertise may be viewed through another lens by estimating (7), which shows the actual empirical relationship between the $X_{k}$ and $z$. This relationship, as we have discussed, is generally not known to the non-expert consumer. Thus the coefficients on the $X_{k}$ are the $\partial z /\left.\partial X_{k}\right|_{T}$ rather than the $\partial z /\left.\partial X_{k}\right|_{A}$. In practical terms, though estimation of (7) may indicate a good fit of $z$ with the $X_{k}$, it is not necessarily the case that consumers have in actuality obtained a good fix on $z$.

The measure of $\partial P / \partial z$ obtained from estimating (6) also reflects the conundrum. The coefficient varies with two effects that are not separately identified: the consumer's valuation of $z$, and the consumer's composite competence at using the surrogate indicators of $z$. Thus a small $\partial P / \partial z$ conflates consumer unawareness with respect to $z$ with consumer apathy. It is possible, moreover, that $\partial P / \partial z$ takes the "wrong" sign, that is, negative for a characteristic that consumers value positively. This occurs when appraisal using available indicators is sufficiently inexpert and fallacious that consumers perceive an unobservable characteristic to be more present when it is in fact less present. Thus an unobservable characteristic desired by consumers could actually be valued negatively by the market.

\subsection{Differences in Appraisal Expertise}

Let us now consider the possibility that not all consumers are equally inexpert: some may be expert appraisers while others are less skilled. Generally, not all people will have the same exposures or experiences that enable them to learn. Even if they did, differences across individuals would lead to different learning with respect to the same exposure. The consequence is differences in knowledge and expertise across individuals.

To model this, let us begin by assuming that consumers differ only with respect to their expertise, and that they are identical with respect to their tastes for product attributes. That is, different consumers $j$ will be characterized by different levels of $\partial z /\left.\partial X_{k}\right|_{A(j)}$ for each $k$. This will tend to result in different levels $\partial P / \partial X_{k(j)}$ for each consumer; however, the direct log valuation components, $\partial P /\left.\partial X_{k}\right|_{D}$, will be the same for all. Appraisal expertise may be defined in an overall sense based on the relative ability of different consumers in essence to fit (7) from the $X_{k}$ using their conjectures about the $\partial z / \partial X_{k}$.Specifically, consumer $j$ ' is "more expert" than $j$ "if $\sum_{k}\left[\left(\partial z /\left.\partial X_{k}\right|_{U\left(j^{\prime}\right)}\right)^{2} \cdot \bar{X}_{k}\right]<\sum_{k}\left[\left(\partial z /\left.\partial X_{k}\right|_{U\left(j^{\prime \prime}\right)}\right)^{2} \cdot \bar{X}_{k}\right]$, where $\bar{X}_{k}=\sum_{i} X_{k i}$; that is, if her weighted sum of squared 
conjectural error is lower. (Note 4) Thus less-expert individuals, so defined, are more prone to errors in distinguishing high- $z$ brands from low- $z$ brands.

The assumption of differences in expertise across consumers has implications for the distribution of consumers across products. This may be seen by considering a simple example in which there are two brands, $H$ and $L$, and two consumers, $j$ ' and $j$ '. Assume $H$ exhibits higher quality with respect to the unobserved characteristic, i.e., $z_{H}>z_{L}$. Suppose the two consumers have identical conjectures with respect to all the $\partial z / \partial X_{k}$ except for one, and for that $k^{\prime}$ let $\left|\partial z / \partial X_{k^{\prime}}\right|_{U\left(j^{\prime}\right)}|<| \partial z /\left.\partial X_{k^{\prime}}\right|_{U\left(j^{\prime \prime}\right)} \mid$. Thus consumer $j$ ” is less expert than $j^{\prime}$. It follows that $j$ " is more likely than $j$ ' to conclude erroneously that $H$ is the low-quality product and $L$ the high-quality product. Thus, given any price pair for the two products, $j$ " is more likely to choose $L$, all else being equal; that is, for a given price, $j$ " is more likely to conclude (erroneously) that $L$ is the better buy based on her erroneous appraisal of $z_{H}$ and $z_{L}$. We can see that consumers who are more expert at appraisal will tend to sort to the high-quality product, while inexpert consumers sort to the low-quality product. Sorting of consumers need not be perfect; however, there will generally be differences in the average expertise of consumers across product pools correlated with the level of unobservable characteristic.

Consumer sorting based on expertise levels has important empirical measurement implications. Recall that the hedonic model requires homogeneous preferences. While this assumption has not been violated per se, the fact that consumers exhibit differences in expertise means that the manifestation of their preferences is heterogeneous. With preference heterogeneity, the hedonic relation taken over all consumers does not trace out a demand function (Bajari \& Benkard, 2005; Rosen, 1974). (Note 5) However, given sorting, it may be quite reasonable to posit consumer homogeneity (or a close approximation) within product pools of a given quality level such that the hedonic relation with respect to each pool traces out a demand function. If so, then the hedonic approach may be appropriately applied separately on product subsamples that vary, using the terminology of our model, as to the value of $z$.

Given the feasibility of hedonic regression on subsamples, it is possible to make inferences about consumers' conjectures relating to the surrogate indicators. Our simple model illustrates. Let us use subscript $E$ to represent the relatively expert consumers that sort to the high-quality product, and $I$ to represent the relative inexpert consumers that sort to the low-quality product. Estimation of (3) restricted to high-quality products provides a composite $\partial P / \partial X_{k(E)}$ for each $k$, while estimating the same equation for low-quality products provides $\partial P / \partial X_{k(I)}$. Using (8), we may write out the implicit components of the coefficients pertaining to experts and inexpert consumers

$$
\begin{aligned}
& \partial P / \partial X_{k(E)}=\partial P /\left.\partial X_{k}\right|_{D}+\partial P / \partial z_{(E)} \cdot \partial z /\left.\partial X_{k}\right|_{A(E)} \\
& \partial P / \partial X_{k(I)}=\partial P /\left.\partial X_{k}\right|_{D}+\partial P / \partial z_{(I)} \cdot \partial z /\left.\partial X_{k}\right|_{A(I)}
\end{aligned}
$$

where $\partial P / \partial z_{(E)}$ and $\partial P / \partial z_{(I)}$ represent, respectively, how experts and inexpert consumers collectively value $z$ while $\partial z /\left.\partial X_{k}\right|_{A(E)}$ and $\left.\partial z\right)\left.^{(I)} \partial X_{k}\right|_{A(I)}$ represent the surrogate indicator capability that each group attributes to $X_{k}$. Note that we are unable to estimate these components directly: $z$ is a constant for the high- and low-quality subsamples, so we cannot include it in the equation. However, (9) and (10) do indicate that the difference in the coefficient estimates for the constant term provides an estimate of $\partial P / \partial z_{(E)}-\partial P / \partial z_{(I)}$.

Subtracting (9) from (10) yields the relative biasin log valuation of inexpert consumers for each $X_{k}$,

$$
\partial P / \partial X_{k(I)}-\partial P / \partial X_{k(E)}=\left(\partial P / \partial z_{(I)}-\partial P / \partial z_{(E)}\right) d z /\left.d X_{k}\right|_{A(I)}-\partial P / \partial z_{(E)} \cdot d z /\left.d X_{k}\right|_{U(E I)}
$$

This bias is the sum of two components: inexpert consumers' relative error in their log valuation of $z$, weighted by their surrogate indicator conjecture about $X_{k}$; and their relative error about the role of $X_{k}$ as indicator, $d z /\left.d X_{k}\right|_{U(E I)} \equiv d z /\left.d X_{k}\right|_{A(E)}-d z /\left.d X_{k}\right|_{A(I)}$, weighted by the experts' $\log$ valuation of $z$. Note that $d z /\left.d X_{k}\right|_{U(E I)}$ represents a generalization of $d z /\left.d X_{k}\right|_{U} \equiv d z /\left.d X_{k}\right|_{T}-d z /\left.d X_{k}\right|_{A}$ from the previous section, in which the conjectures of the relative experts who sort to the high-quality product replace the total information content represented by the subscript $T$. We observe that the intrinsic valuation of $X_{k}$ plays no role in the bias; this follows from the presumption that all consumers have identical tastes for product attributes. Intuitively, the relative bias tells us how $\log$ valuations of $X_{k}$ purely as a surrogate indicator differ for consumers sorting to low-quality versus high-quality products. 
A corresponding relative conjectural error, $\left.\mu_{k(E I)} \equiv \frac{\partial z}{\partial X_{k}}\right|_{A(I)}\left|\frac{\partial z}{\partial X_{k}}\right|_{A(E)}$, generalizes $\mu_{k}$; here, overshooting, undershooting, and fallacy by inexpert consumers relative to the experts may be defined, respectively, as $\mu_{k(E I)}>1, \mu_{k(E I)} \in(0,1)$, and $\mu_{k(E I)}<0$. Whereas inferences could not drawn about $\mu_{k}$, the sorting of consumers allows us to draw inferences about $\mu_{k(E I)}$, based on (11). Table 2 summarizes. Inferences depend upon the sign of $\partial P / \partial X_{k(I)}-\partial P / \partial X_{k(E)}$, whether the unobservable characteristic is positively or negatively valued, and whether $X_{k}$ is a significant positive or negative surrogate indicator with respect to the unobservable characteristic based on estimation of (7). The table's results depend additionally on the maintained assumption that both experts and inexpert consumers consistently and correctly value $z$ as positive or negative; this enables us to posit $\partial P / \partial z_{(E)}>\partial P / \partial z_{(I)}>0$ for a positive $z$, and $\partial P / \partial z_{(E)}<\partial P / \partial z_{(I)}<0$ for a negative $z$. We also maintain the assumption that expert consumers are sufficiently expert that they are not fallacious, though the inexpert consumers could be.

Table 2. Inexpert consumers' relative conjectural error with respect to $X_{k}$

\begin{tabular}{llll}
\hline & $\begin{array}{l}\mathrm{X}_{\mathrm{k}} \text { is a significant } \\
\text { positive indicator }\end{array}$ & $\begin{array}{l}\mathrm{X}_{\mathrm{k}} \text { is a significant } \\
\text { negative indicator }\end{array}$ & $\mathrm{X}_{\mathrm{k}}$ is insignificant \\
\hline$\partial \mathrm{P} / \partial \mathrm{X}_{\mathrm{k}(\mathrm{I})}-\partial \mathrm{P} / \partial \mathrm{X}_{\mathrm{k}(\mathrm{E})}, \mathrm{z}$ & Large Overshoot & $\begin{array}{l}\text { Fallacy, Undershoot, or } \\
\text { Small Overshoot } \\
\text { same sign }\end{array}$ & $\begin{array}{l}\text { ("FUSO") } \\
\text { Indeterminate }\end{array}$ \\
$\begin{array}{ll}\partial \mathrm{P} / \partial \mathrm{X}_{\mathrm{k}(\mathrm{I})}-\partial \mathrm{P} / \partial \mathrm{X}_{\mathrm{k}(\mathrm{E})}, \mathrm{z} \\
\text { opposite sign }\end{array}$ & $\begin{array}{l}\text { Fallacy, Undershoot, or } \\
\text { Small Overshoot ("FUSO") }\end{array}$ & Large Overshoot & Indeterminate \\
\hline
\end{tabular}

Table 2 shows that the researcher may mainly distinguish only situations in which inexpert consumers overshoot substantially from situations in which they do not. For example, when a significant positive surrogate indicator of a positively valued unobservable characteristic corresponds to a positive bias in inexpert consumers' log valuations, it is clear that inexpert consumers assign more surrogate indicator value to the characteristic than is warranted. But when these conditions correspond to a negative bias, it is impossible to distinguish whether the conjectural error is characterized by fallacy, undershoot, or even a small overshoot. A negative bias follows for modest overshooting because a negative first term may overwhelm a positive second term in (11) (Note 6): intuitively, the inexpert consumers' failure to identify the positive unobservable characteristic when it is present causes them to undervalue its presence in general. This drags down the surrogate indicator value of all observable characteristics. Meanwhile, in the case of a variable not being a significant surrogate indicator as revealed in the estimation of (7), the relative conjectural error is indeterminate: since we cannot reject the hypothesis that the observable characteristic in question is unhelpful as an indicator, we are unable to determine whether inexpert consumers have over- or under-relied upon it as such.

\section{An Application: The Market for Black Cohosh}

A topical exemplar of the uncertainty problem consumers face when a key product quality variable is unobservable, the market for the dietary supplement black cohosh provides the data we will use for demonstrating the method presented in the previous section. With overall sales of dietary supplements in the United States estimated at $\$ 28.7$ billion in 2010 and continuing to grow rapidly, (Note 7) research results relating to black cohosh and similar products have potentially far-reaching significance.

\subsection{Background}

A plant native to North America, black cohosh (Latin name Actaea racemosa, formerly Cimicifuga racemosa) was used historically by Native Americans for a number of medicinal purposes. Over the past 50 years it has gained popularity in Europe, and more recently in North America, as an herbal supplement for treating menopausal symptoms. Randomized clinical trials studying the effects of black cohosh have produced mixed results, some showing benefit, and others not (Kronenberg \& Fugh-Berman, 2002; Fabricant \& Farnsworth, 2005; Borrelli \& Ernst, 2008). Yet, despite the uncertainty associated with the trial findings, black cohosh remains very popular, ranked recently as one of the top 10 dietary supplements based on retail sales in the United States (Cavaliere, Rea, Lynch, \& Blumenthal, 2009). Continued strong interest in this supplement suggests that consumers generally believe it to be effective in treating menopause. 
As a dietary supplement, black cohosh is subject to regulation in the United States by the Food and Drug Administration (FDA) under the Dietary Supplement Health and Education Act (DSHEA). Following DSHEA's main premise, the rules that cover labeling and good manufacturing practices for dietary supplements more closely resemble those that govern foods than the FDA's rigorous drug regulations. Accordingly, supplements require no premarket clinical testing or approval. Since DSHEA was enacted in 1994, the number of products to which it has applied has grown from 4,000 to approximately 30,000. Over the same period, FDA funding for supplement oversight has declined. Consequently, the agency has recently faced severe constraints in its efforts to enforce its rules against supplement mislabeling and contamination (Wechsler, 2007).

Mislabeling of black cohosh has been recently documented. In a laboratory study of 11 products labeled as pure black cohosh, Jiang, Kronenberg, Nuntanakorn, Qiu, \& Kennelly (2006) detected adulteration in four. Three of these products contained marker compounds for a lower-cost Asian Actaea species, but not those expected for American black cohosh. The fourth contained both Asian Actaea and American black cohosh. The medicinal uses of Asian Actaea differ from those of American black cohosh, and the health consequences of substitution are not known (National Pharmacopoeia Committee, 2005, p. 50).

Given lax product quality and truth-in-labeling regulation, it seems appropriate to view product authenticity as a relevant, unobservable quality variable over which consumers of black cohosh experience real uncertainty. This uncertainty and the consumer inference problem it creates are likely compounded by the lack of dispositive evidence concerning the effectiveness of even authentic black cohosh.

\subsection{Data}

We visited 20 stores in New York City and the lower Hudson River Valley and collected non-promotional retail prices for all black cohosh tablet, caplet, capsule, and softgel products sold in the stores. (Note 8) We included only "single-herb" black cohosh, excluding multi-product formulations that combined black cohosh with other potentially active ingredients, such as vitamins or soy isoflavones. Some of the products sampled were sold at multiple stores, resulting in multiple price observations per product in certain cases. In total, 55 price observations were made representing 38 distinct products labeled as black cohosh. (Note 9)

In addition to the price data, other publicly observable product information was obtained. For each distinct product, we collected all the information appearing on the label, including ingredients lists and the precise wording of all label verbiage. Using standard Internet search techniques (e.g., Google), we also found and collected online consumer ratings of the brands represented. (Note 10) All data on observable characteristics were collected during the summer and fall of 2007.

To measure product authenticity, we conducted a laboratory analysis of the 38 products, following the procedure described by Jiang et al. (2006, pp. 3243-3245). Specifically, we employed a combined method of high-performance liquid chromatography - photodiode array detection (HPLC-PDA) and selected ion monitoring liquid chromatography - mass spectrometry (SIM LC-MS).The method observes multiple ions in the products in order to evaluate whether the products contain black cohosh. The results of the authentication analysis were roughly consistent with Jiang et al.'s results. 25 out of the 38 products were found to contain black cohosh, while the other 13 did not. Thus, approximately $66 \%$ of products contained black cohosh in the current study, as compared to $73 \%$ analyzed by Jiang et al. For obvious reasons, we withhold identifying information on the products studied, though in what follows we do report average prices and regression results incorporating the authenticity data.

In all, in addition to PRICE (the retail price) and AUTHENTICITY (binary indicator of whether the product contained black cohosh or not), the following variables were populated for each observation:

1) NYC, a dummy variable indicating whether the store where the price was observed was located in New York City;

2) RETAILER BRAND, a dummy variable indicating whether the product is a retailer's brand (e.g., Whole Foods, Vitamin Shoppe);

3) INGREDIENTS, the number of commonly-perceived "active" ingredients listed on the label;

4) VEGGIE, a dummy variable indicating whether the product is suitable for vegetarians, based on the ingredients or an explicit label affirmation;

5) KOSHER, a dummy variable indicating whether the product is kosher, based on an explicit label affirmation; 
6) STANDARDIZED, a dummy variable indicating whether the label claims the product contains a standardized component or set of components, as determined by industry-recognized methods (a quality assurance measure);

7) SIDE EFFECTS, a dummy variable indicating whether the label warns of side effects;

8) SAFE, a dummy variable indicating whether the label contains the word "safe" or some derivative (e.g., "safely");

9) RATED, a dummy variable indicating whether an online consumer rating could be located for the particular brand of black cohosh;

10) SUM OF RATINGS, the total of the ratings located for the brand (with individual ratings normalized to a 1-point scale);

11) TIME SUPPLY, the number of days of supplement supplied per package, calculated as the number of units (e.g., tablets) per package divided by the number of units per day in the recommended dosage (or the maximum number of units per day in those cases where a range was given);

12) CERTIFIED, a dummy variable indicating whether the label contains the word "certified";

13) GUARANTEED, a dummy variable indicating whether the label contains the word "guarantee" or some derivative;

14) CLAIMS, a dummy variable indicating whether the label makes an affirmative therapeutic claim with respect to a specific symptom.

Table 3. Displays descriptive statistics for our data (Note 11)

\begin{tabular}{lllll}
\hline & Mean & St. Dev. & Min. & Max \\
\hline Full sample $(N=55)$ & & & & \\
PRICE & 12.782 & 6.404 & 4.790 & 28.990 \\
NYC & 0.764 & 0.429 & 0.000 & 1.000 \\
RETAILER BRAND & 0.164 & 0.373 & 0.000 & 1.000 \\
INGREDIENTS & 1.018 & 0.135 & 1.000 & 2.000 \\
VEGGIE & 0.418 & 0.498 & 0.000 & 1.000 \\
KOSHER & 0.055 & 0.229 & 0.000 & 1.000 \\
STANDARDIZED & 0.745 & 0.440 & 0.000 & 1.000 \\
SIDE EFFECTS & 0.291 & 0.458 & 0.000 & 1.000 \\
SAFE & 0.182 & 0.389 & 0.000 & 1.000 \\
RATED & 0.400 & 0.494 & 0.000 & 1.000 \\
TIME SUPPLY & 47.267 & 39.550 & 2.250 & 240.000 \\
CERTIFIED & 0.091 & 0.290 & 0.000 & 1.000 \\
GUARANTEED & 0.345 & 0.480 & 0.000 & 1.000 \\
CLAIMS & 0.345 & 0.480 & 0.000 & 1.000 \\
AUTHENTICITY & 0.727 & 0.449 & 0.000 & 1.000 \\
Subsample of online-rated products $(N=22)$ & & & & \\
SUM OF RATINGS & 9.277 & 7.298 & 0.800 & 15.980 \\
\hline
\end{tabular}

See text for description of variables

\subsection{Surrogate Indicator Estimation on the Full Sample}

Measurement of inexpert consumers' relative conjectural errors requires two sets of estimates: full-sample estimates of the role of the observable product characteristics in indicating unobservable authenticity; and hedonic estimates on authentic and non-authentic product subsamples to obtain the log valuations of the observable characteristics by expert and inexpert consumers, respectively. To obtain the former, we estimated(7), including all variables \#1-14 for the $X_{k}$. The results are shown in Table 4.As discussed in Section 3, these results show the true empirical relationship of the observables to unobserved authenticity: true positive indicators (e.g., KOSHER) take positive signs, while true negative indicators (e.g., STANDARIZED) take negative signs. The relationship that inexpert consumers infer between the observables and authenticity will tend to differ from what the results in Table 4 show. 
Table 4. Full-sample regression results - indicators of authenticity

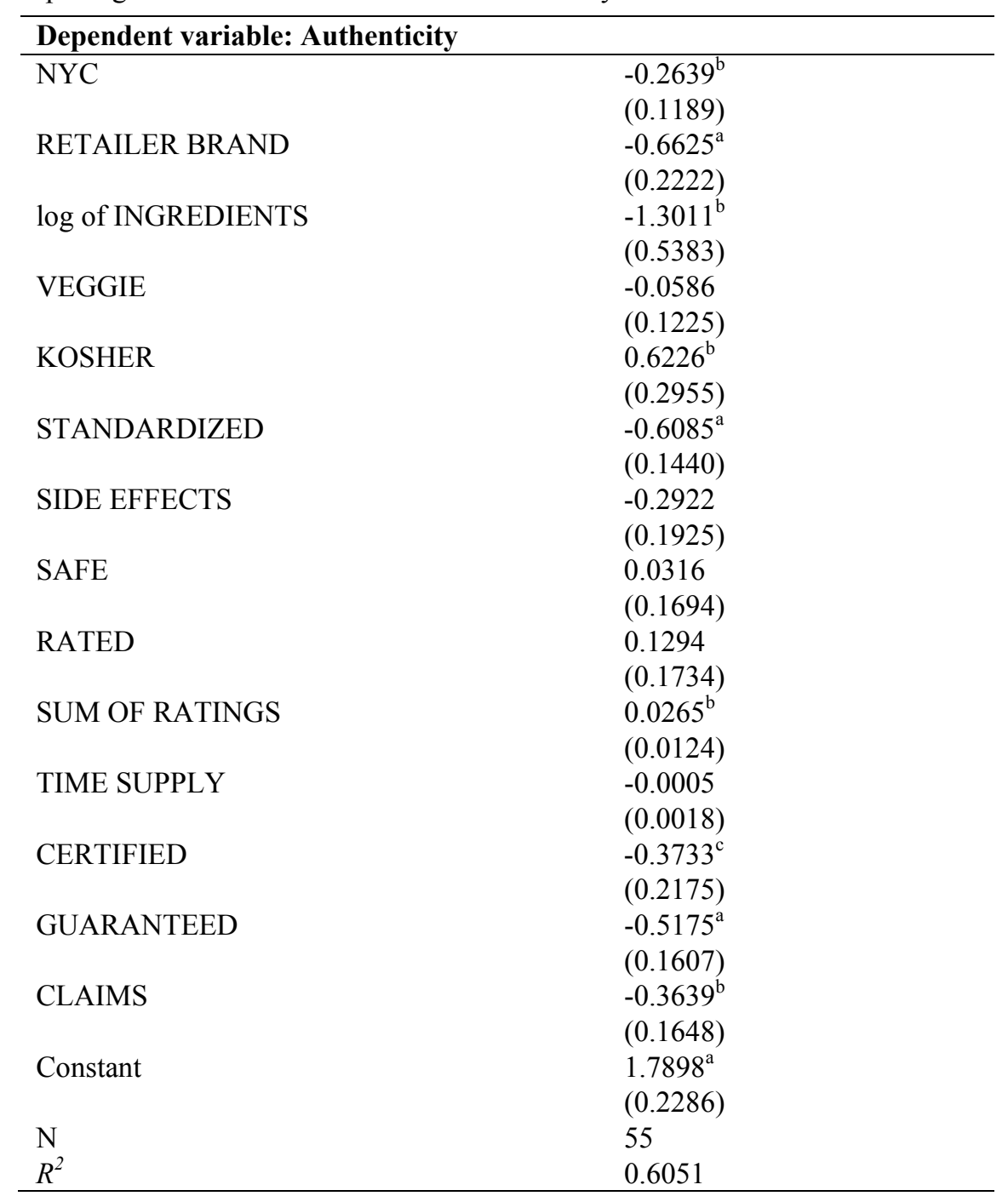

Standard errors are in parentheses

${ }^{a}$ significant at $1 \%$; ${ }^{b}$ significant at $5 \%$; ${ }^{c}$ significant at $10 \%$

See text for description of variables

Several of the observable characteristics we tracked have a significant relationship to authenticity. It is interesting to note that a number of label words that seem intended to reassure consumers about authenticity turn out to be significant negative indicators of actual authenticity: CERTIFIED, GUARANTEED, and CLAIMS (as well as STANDARDIZED) all take significant negative coefficients in the regression. There may be a number of possible marketing explanations for why these words appear on labels. However, their persistent presence seems to point to the inexpertise of a significant portion of consumers. After all, if consumers were all expert appraisers, they would figure out quickly that these words counter-indicate authenticity and would tend to steer clear of the associated products. This would then induce marketers to remove the words from their products' labels.

It is also interesting to note that our $X_{k}$, taken together, explain more than three-fifths of the total variation in authenticity. It is fair to say that the potential appears to exist for effective appraisal of black cohosh by knowledgeable consumers.

\subsection{Hedonic Estimation on Quality-differentiated Subsamples: Inferences Based on Sorting}

We now turn to the second component in our conjectural error measurement procedure: hedonic estimation on the authentic and non-authentic product subsamples. We estimated (3), including again all variables \#1-14 for the $X_{k}$. The first two columns of Table 5 display the results of this estimation. A number of the explanatory 
variables are omitted from the regressions for either the authentic or non-authentic model because they take a constant value across the corresponding subsample, and so provide no variation as a basis for estimating a coefficient. Their omission from the regression only affects the size of the constant term, and so has no relevance to the coefficients on included explanatory variables. However, it makes it impossible to compare constant terms between the models as a measure of the relative valuation of the unobservable characteristic, per our discussion in Section 3.

Table 5. Hedonic regression results and estimates of relative bias in valuation and conjectural error

\begin{tabular}{|c|c|c|c|c|}
\hline \multicolumn{5}{|c|}{ Dependent variable: log of PRICE } \\
\hline \multirow{6}{*}{ NYC } & $(1)$ & (2) & & \\
\hline & Authentic & Non-authentic & Relative Bias of & Relative Conjectural \\
\hline & Subsample & Subsample & Inexpert & Error \\
\hline & $(\mathrm{OLS})$ & $(\mathrm{OLS})$ & Consumers & \\
\hline & $-0.1671^{c}$ & Omitted & & \\
\hline & $(0.0968)$ & & & \\
\hline \multirow[t]{2}{*}{ RETAILER BRAND } & $-1.4214^{a}$ & $-1.3401^{\mathrm{c}}$ & 0.0813 & FUSO \\
\hline & $(0.3069)$ & $(0.5354)$ & & \\
\hline $\log$ of INGREDIENTS & Omitted & Omitted & & \\
\hline \multirow[t]{2}{*}{ VEGGIE } & 0.2003 & 0.5907 & 0.3904 & Indeterminate \\
\hline & $(0.1600)$ & $(0.3413)$ & & \\
\hline \multirow[t]{2}{*}{ KOSHER } & -0.0233 & Omitted & & \\
\hline & $(0.2418)$ & & & \\
\hline \multirow[t]{2}{*}{ STANDARDIZED } & 0.2868 & Omitted & & \\
\hline & $(0.1698)$ & & & \\
\hline \multirow[t]{2}{*}{ SIDE EFFECTS } & -0.0347 & 0.8826 & 0.9173 & Indeterminate \\
\hline & $(0.1799)$ & $(0.7771)$ & & \\
\hline \multirow[t]{2}{*}{ SAFE } & $0.6069^{\mathrm{b}}$ & -0.1791 & -0.7860 & Indeterminate \\
\hline & $(0.2873)$ & $(0.8238)$ & & \\
\hline \multirow[t]{2}{*}{ RATED } & $-1.0207^{a}$ & Omitted & & \\
\hline & $(0.2174)$ & & & \\
\hline \multirow[t]{2}{*}{ SUM OF RATINGS } & $0.0512^{\mathrm{a}}$ & -0.8145 & -0.8657 & FUSO \\
\hline & $(0.0143)$ & $(0.4980)$ & & \\
\hline \multirow[t]{2}{*}{ TIME SUPPLY } & $0.0135^{\mathrm{a}}$ & $0.0089^{\mathrm{b}}$ & -0.0046 & Indeterminate \\
\hline & $(0.0033)$ & $(0.0028)$ & & \\
\hline \multirow[t]{2}{*}{ CERTIFIED } & 0.1185 & 2.4236 & 2.3051 & FUSO \\
\hline & $(0.2351)$ & $(1.2730)$ & & \\
\hline \multirow[t]{2}{*}{ GUARANTEED } & $-0.3631^{b}$ & -0.0827 & 0.2804 & FUSO \\
\hline & $(0.1729)$ & $(0.4860)$ & & \\
\hline \multirow[t]{2}{*}{ CLAIMS } & -0.2532 & -0.5029 & -0.2497 & Large overshoot \\
\hline & $(0.1819)$ & $(0.4860)$ & & \\
\hline \multirow[t]{2}{*}{ Constant } & $2.1782^{\mathrm{a}}$ & $2.3967^{\mathrm{a}}$ & & \\
\hline & $(0.2387)$ & $(0.4189)$ & & \\
\hline $\mathrm{N}$ & 40 & 15 & & \\
\hline$R^{2}$ & 0.8196 & 0.7802 & & \\
\hline
\end{tabular}

Standard errors are in parentheses

${ }^{\mathrm{a}}$ significant at $1 \%$; ${ }^{\mathrm{b}}$ significant at $5 \%$; ${ }^{\mathrm{c}}$ significant at $10 \%$

$\mathrm{FUSO}=$ fallacy, undershoot, or small overshoot

See text for description of variables. Variables that took constant values within a subsample were omitted from the corresponding regression, as indicated.

There are stark differences in the coefficients estimated for the explanatory variables on the two subsamples. Under the assumption that the buyers of authentic and non-authentic black cohosh do not differ in their intrinsic valuation of observable characteristics, these differences represent differences in valuation of the observable characteristics purely as surrogate indicators. Given that consumers more capable at appraising black cohosh likely tend to sort to the authentic products, the coefficient differences may be characterized as representing the 
relative bias of the relatively inexpert consumers who buy the non-authentic products. We display this bias explicitly in the third column of Table 5 .

We use our relative bias measures and the decomposition in (11) to determine the relative conjectural error of the inexpert consumers. We employ the classification in Table 2, taking the presumption that authenticity is a positively valued quality, and using the information in Table 4 on which variables are significant positive or significant negative surrogate indicators. The last column of Table 5 reports our findings.

With respect to most significant surrogate indicators, relatively inexpert consumers appear to undershoot - or else, entertain fallacies or modestly overshoot - in their conjectures. This suggests either unawareness or tentativeness about most of the indicators of authenticity. But there is one exception: inexpert consumers overshoot substantially with respect to drawing negative inferences about authenticity from the presence of specific therapeutic claims on the label. That is, while they correctly infer that therapeutic claims are a significant negative indicator of authenticity, they place too much weight on them. We will discuss the possible implications of this finding in the next section.

\section{Conclusion}

In this paper we have proposed a method for measuring the conjectural errors that inexpert consumers make with respect to using observable characteristics as surrogate indicators of an unobservable product quality variable. The approach uses data on the quality variable - observable to researchers, though not to consumers - as a basis for creating subsamples for separate hedonic log-price regressions. Given the assumption that consumers sort between high- and low-quality products based on their product appraisal expertise, such regressions yield distinct marginal values accorded to observed characteristics by expert and inexpert consumers. Combining the estimates with data on the actual empirical relationship of the quality variable to the indicators enables the researcher to measure the conjectures of the expert and inexpert consumers, and the associated relative errors made by the latter.

We applied this method to data on observable characteristics of a set of brands of the dietary supplement black cohosh, paired to observations of consumer-unobservable product authenticity. We found that, whereas inexpert consumers probably err on the side of being too tentative in their use of most surrogate indicators, they devalued products making therapeutic claims on their labels more than experts did. Thus, while the presence of claims correlate negatively with product authenticity, suggesting that they are appropriately viewed as a negative indicator, inexpert consumers appear to have construed too much about authenticity from this variable. Bogus supplement claims have received prominent treatment in the press, (Note 12) and it is possible that their consequent salience causes some individuals, particularly those who are less skilled at appraising products, to focus too much on them in their assessment of supplement quality. These same individuals may suboptimally neglect other sources of information, including other product label cues.

From a managerial perspective, research along the lines of the methods demonstrated here may yield a number of useful applications. Performing hedonic analysis separately on expert and inexpert consumers may allow managers to develop targeted pricing strategies that account for differences in how these two groups value product characteristics as indicators of unobservable qualities. Such findings may also allow for targeted product and promotion strategies that emphasize product attributes of interest to each group. Observed differences in the conjectural errors with respect to surrogate indicators that inexpert consumers make relative to experts provide additional information for managers that may be useful in promotional targeting. In the market for black cohosh, for example, managers might conclude from our study's findings - perhaps tentatively, given its small sample that a product targeted to less sophisticated consumers should tone down therapeutic label claims (e.g., "ends hot flashes within 48 hours"), whatever else the benefits of including such claims on the label might be. Products marketed with such claims to unsophisticated consumers would have to be priced lower, all else equal. Consistent with product labeling, advertisements of black cohosh products directed to inexpert individuals should perhaps also eschew emphasis on the product's therapeutic claims, while those directed to relatively sophisticated consumers might not. As discussed in the introduction, there are many marketing contexts in which researchers may gain access to relevant consumer-unobservable product characteristics across brands, allowing for the techniques demonstrated in this paper to be applied quite broadly. Overall, our study highlights the value of accounting for consumer-unobservable characteristics in marketing research.

Further work needs to be done. The present study was limited by its small sample size and should therefore be considered largely as an initial proof of concept. In particular, the coefficient estimates associated with the two subsamples likely included a substantial amount of noise, and our interpretations of the differences and the associated conjectural errors should be weighted accordingly. The study was also limited by our reliance on list 
prices in place of transacted prices. For us to know definitively that consumers have valued a product at a certain price, we would need to witness actual transactions at that price. Undoubtedly, a significant share of transactions at the stores covered by our study occurred at list prices, but we do not know what share, nor do we know the discounted prices that applied to the remaining transactions. In using list prices, we effectively assume that discounting has been applied equally across all SKUs in the study, a characteristic that our study shares with other hedonic analyses that have used list prices (e.g., Gandal, 1994; Roe et al., 2001).One objective for future research would be to test the application of the study's approach using scanner data. More generally, replication of our method in other contexts would be helpful in demonstrating its uses. Product markets with prominent experience and/or credence good qualities pose good candidates, particularly where important managerial or policy issues remain unresolved.

One example involving provocative policy issues that relate to marketing practices and consumer welfare is the market for illegal drugs. Public policy has focused on limiting supply through seizure, with mixed results.One consequence of supply-chain pressure has been that sellers "cut" their product with baser substances before selling it. (Note 13) In regard to reductions in drug purity and their implications for drug policy evaluation, a number of questions need to be answered. To what extent do observable characteristics provide evidence of adulterated products? What observable characteristics are most influential in stimulating recognition of adulteration?Assuming some buyers are less sophisticated than others, what sorts of conjectural errors in drug purity evaluation do inexpert buyers make relative to experts? Do supply-chain pressure and consequent effects on drug purity have consequences for which type of buyer is predominantly purchasing the product?

\section{References}

Alba, J. W., \& Hutchinson, J. W. (1987). Dimensions of consumer expertise. Journal of Consumer Research, 13(4), 411-454. http://dx.doi.org/10.1086/209080

Armstrong, M., \& Chen, Y. (2009).Inattentive consumers and product quality. Journal of the European Economic Association, 7(2-3), 411-422. http://dx.doi.org/10.1162/JEEA.2009.7.2-3.411

Bajari, P., \& Benkard, C. L. (2005). Demand estimation with heterogeneous consumers and unobserved product characteristics: A hedonic approach. Journal of Political Economy, 113(6), 1239-1276. http://dx.doi.org/10.1086/498586

Borrelli, F., \& Ernst, E. (2008). Black cohosh (Cimicifugaracemosa) for menopausal symptoms: A systematic review of its efficacy, Pharmacological Research, 58(1), 8-14. http://dx.doi.org/10.1016/j.phrs.2008.05.008

Broniarczyk, S. M., \& Alba, J. W. (1994). The role of consumers' intuitions in inference making. Journal of Consumer Research, 21(3), 393-407. http://dx.doi.org/10.1086/209406

Brook, T. (1998). The confusions of pleasure: Commerce and culture in Ming China. Berkeley: University of California Press.

Brucks, M., Zeithaml, V. A., \& Naylor, G. (2000).Price and brand name as indicators of quality dimensions for consumer durables. Journal of the Academy of Marketing Science, 28(3), 359-374. http://dx.doi.org/10.1177/0092070300283005

Burton, S., \& Lichtenstein, D. R. (1989).The relationship between perceived and objective price-quality. Journal of Marketing Research, 26(4), 429-443. http://dx.doi.org/10.2307/3172763

Burton, S., \& Lichtenstein, D. R. (1990). Assessing the relationship between perceived and objective price-quality: A replication. Advances in Consumer Research, 17(1), 715-722.

Cavaliere, C., Rea, P., Lynch, M. E., \& Blumenthal, M. (2009). Herbal supplement sales experience slight increase in 2008. HerbalGram, 82, 58-61.

Chiou, J. (2003). The impact of country of origin on pretrial and posttrial product evaluations: The moderating effect of consumer expertise. Psychology \& Marketing, 20(10), 935-954. http://dx.doi.org/10.1002/mar.10103

Darby, M. R., \&Karni, E. (1973). Free competition and the optimal amount of fraud. Journal of Law and Economics, 16(1), 67-88. http://dx.doi.org/10.1086/466756

Dick, A., Chakravarti, D., \&Biehal, G. (1990). Memory-based inferences during consumer choice. Journal of Consumer Research, 17(1), 82-93. http://dx.doi.org/10.1086/208539 
Dulleck, U., \& Kerschbamer, R. (2006). On doctors, mechanics, and computer specialists: The economics of credence goods. Journal of Economic Literature, 44(1), 5-42. http://dx.doi.org/10.1257/002205106776162717

Erdem, T., Keane, M. P., \& Sun, B. (2008). A dynamic model of brand choice when price and advertising signal product quality. Marketing Science, 27(6), 1111-1125. http://dx.doi.org/10.1287/mksc.1080.0362

Fabricant, D. S., \& Farnsworth, N. R. (2005). Black cohosh (Cimicifugaracemosa). In P. M. Coates (Ed.), Encyclopedia of dietary supplements (pp. 41-54). Boca Raton, FL: Marcel Dekker.

Gabaix, X., \& Laibson, D. (2006). Shrouded attributes, consumer myopia, and information suppression in competitive markets. Quarterly Journal of Economics, 121(2), 505-540. http://dx.doi.org/10.1162/qjec.2006.121.2.505

Gandal, N. (1994). Hedonic price indexes for spreadsheets and an empirical test for network externalities. RAND Journal of Economics, 25(1), 160-170. http://dx.doi.org/10.2307/2555859

Godes, D., \& Mayzlin, D. (2004). Using online conversations to study word-of-mouth communication. Marketing Science, 23(4), 545-560. http://dx.doi.org/10.1287/mksc.1040.0071

Gomstyn, A. (2010). "Dangerous" herbal supplement claims under fire in government report. News article. ABC News. $\quad$ Retrieved $\quad$ March $22, \quad 2011$ from http://abcnews.go.com/Business/Retirement/herbal-supplement-claims-fire-govt-report/story?id=10738605.

Heifitz, A., Meier, M., \& Schipper, B. C. (2006). Interactive unawareness. Journal of Economic Theory, 130(1), 78-94. http://dx.doi.org/10.1016/j.jet.2005.02.007

Huang, C. L., \& Lin, B.-H. (2007). A hedonic analysis of fresh tomato prices among regional markets. Review of Agricultural Economics, 29(4), 783-800. http://dx.doi.org/10.1111/j.1467-9353.2007.00387.x

Jiang, B., Kronenberg, F., Nuntanakorn, P., Qiu, M.-H., \& Kennelly, E. J. (2006). Evaluation of the botantical authenticity and phytochemical profile of black cohosh products by high-performance liquid chromatography with selected ion monitoring liquid chromatography-mass spectrometry. Journal of Agricultural and Food Chemistry, 54(9), 3242-3253. http://dx.doi.org/10.1021/jf0606149

Jo, M.-S. (2005). Why country of origin effects vary in consumers' quality evaluation: A theoretical explanation and implications for country of origin management. Journal of Global Marketing, 19(1), 5-25. http://dx.doi.org/10.1300/J042v19n01_02

Johnson, A. R., \& Folkes, V. S. (2007). How consumers' assessments of the difficulty of manufacturing a product influence quality perceptions. Journal of the Academy of Marketing Science, 35(3), 317-328. http://dx.doi.org/10.1007/s11747-007-0026-4

Johnson, R. D., \& Levin, I. P. (1985). More than meets the eye: The effect of missing information on purchase evaluations. Journal of Consumer Research, 12(2), 169-177. http://dx.doi.org/10.1086/208505

Kristensen, K. (1984). Hedonic theory, marketing research, and the analysis of complex goods. International Journal of Research in Marketing, 1(1), 17-36. http://dx.doi.org/10.1016/0167-8116(84)90005-3

Kronenberg, F., \& Fugh-Berman, A. (2002). Complementary and alternative medicine (CAM) for menopausal symptoms: A review of randomized control trials. Annals of Internal Medicine, 137(10), 805-813.

Lancaster, K. J. (1966). A new approach to consumer theory. Journal of Political Economy, 74(2), 132-157. http://dx.doi.org/10.1086/259131

Letizia, P., Greenfield, V. A., \& Reuter, P. (2009). The world heroin market: Can supply be cut? Oxford: Oxford University Press.

Li, J. (2009). Information structures with unawareness. Journal of Economic Theory, 144(3), 977-993. http://dx.doi.org/10.1016/j.jet.2008.10.001

Liu, Z. (2008). The dirty face problem with unawareness. The B.E. Journal of Theoretical Economics, 8(1) (Topics), Article 28. http://dx.doi.org/10.2202/1935-1704.1441

Maheswaran, D. (1994). Country of origin as a stereotype: Effects of consumer expertise and attribute strength on product evaluations. Journal of Consumer Research, 21(2), 354-365. http://dx.doi.org/10.1086/209403

Maheswaran, D., Sternthal, B., \& Gürhan, Z. (1996). Acquisition and impact of consumer expertise. Journal of Consumer Psychology, 5(2), 115-133. http://dx.doi.org/10.1207/s15327663jcp0502_02 
Mason, K., Burton, T. J. S., \& Roach, D. (2001). The accuracy of brand and attribute judgments: The role of information relevancy, product experience, and attribute-relationship schemata. Journal of the Academy of Marketing Science, 29(3), 307-317. http://dx.doi.org/10.1007/BF02890787

Mast, C. (2011). Supplement sales continue strong growth trajectory in 2010. News article. New Hope 360. $\begin{array}{llll}\text { Retrieved } \quad \text { August } & 2011 & \text { from }\end{array}$ $\mathrm{http}: / /$ newhope360.com/supplements/supplement-sales-continue-strong-growth-trajectory-2010.

Mitchell, A. A., \& Dacin, P. A. (1996). The assessment of alternative measures of consumer expertise. Journal of Consumer Research, 23(3), 219-239. http://dx.doi.org/10.1086/209479

Nagler, M. G. (1993). Rather bait than switch: deceptive advertising with bounded consumer rationality. Journal of Public Economics, 51(3), 359-378. http://dx.doi.org/10.1016/0047-2727(93)90071-Z

National Pharmacopoeia Committee. (2005). Chinese pharmacopoeia 2005A. Beijing: Chemistry Industry Press.

Pakes, A. (2003). A reconsideration of hedonic price indexes with an application to PC's. American Economic Review, 93(5), 1578-1596. http://dx.doi.org/10.1257/000282803322655455

Pinson, C. (1986). An implicit product theory approach to consumers' inferential judgments about products. International Journal of Research in Marketing, 3(1), 19-38. http://dx.doi.org/10.1016/0167-8116(86)90040-6

Quester, P. G., Dzever, S., \& Chetty. S. (2000). Country-of-origin effects on purchasing agents' product perceptions: An international perspective. Journal of Business \& Industrial Marketing, 15(7), 479-490. http://dx.doi.org/10.1108/08858620010351706

Rao, A. R., \& Monroe, K. B. (1989). The effect of price, brand name, and store name on buyers' perceptions of product quality: An integrative review. Journal of Marketing Research, 26(3), 351-357. http://dx.doi.org/10.2307/3172907

Roe, B., Teisl, M. F., Levy, A., \& Russell, M. (2001). US consumers' willingness to pay for green electricity. Energy Policy, 29(11), 917-925. http://dx.doi.org/10.1016/S0301-4215(01)00006-4

Rosen, S. (1974). Hedonic prices and implicit markets: Product differentiation in pure competition. Journal of Political Economy, 82(1), 34-55. http://dx.doi.org/10.1086/260169

Ross, W. T., Jr., \& Creyer, E. H. (1992). Making inferences of missing information: The effects of existing information. Journal of Consumer Research, 19(1), 14-25. http://dx.doi.org/10.1086/209282

Salop, S., \& Stiglitz, J. (1977). Bargains and ripoffs: A model of monopolistically competitive price dispersion. Review of Economic Studies, 44(3), 493-510. http://dx.doi.org/10.2307/2296903

Sanbonmatsu, D. M., Kardes, F. R., \& Sansone, C. (1991). Remembering less and inferring more: Effects of time of judgment on inferences about unknown attributes. Journal of Personality and Social Psychology, 61(4), 546-554. http://dx.doi.org/10.1037/0022-3514.61.4.546

Sanbonmatsu, D. M., Kardes, F. R., Houghton, D. C., Ho, E. A., \& Posavac, S. S. (2003). Overestimating the importance of the given information in multiattribute consumer judgment. Journal of Consumer Psychology, 13(3), 289-300. http://dx.doi.org/10.1037/0022-3514.61.4.546

Völckner, F., \& Hofmann, J. (2007). The price-perceived quality relationship: A meta-analytic review and assessment of its determinants. Marketing Letters, 18(3), 181-196. http://dx.doi.org/10.1007/s11002-007-9013-2

Wechsler, J. (2007). Ensuring quality for dietary supplements. Pharmaceutical Technology, August, 28-38.

West, G. E., Larue, B., Gendron, C., \& Scott, S. L. (2002). Consumer confusion over the significance of meat attributes: The case of veal. Journal of Consumer Policy, 25(1), 65-88. http://dx.doi.org/10.1023/A:1014514601863

\section{Notes}

Note 1. Unawareness may be described by subjective state spaces that may contain full factual information but lack awareness information necessary for reasoning with respect to relevant uncertainties. Thus, the agent possesses facts, but they do not "ring a bell" in a way needed to make a relevant inference. Put another way, the possibility of the inference does not "occur" to the agent. For discussions, see Heifetz, Meier, \& Schipper (2006); Li (2009); and Liu (2008). 
Note 2. We emphasize "express" here because, even though consumers may all have the same preferences over characteristics, differences in expertise will cause consumers to act as if their preferences differ. This would violate the requirements of the hedonic model. See Section 3.

Note 3. People obtain indications about unobservable product qualities from a number of sources, including advertising content and intensity, consumption experiences, and prices (e.g., Erdem, Keane, \& Sun, 2008); as well as word-of-mouth communication by other consumers, including online product reviews (Godes \& Mayzlin, 2004). Such sources of product indication may be viewed, in the context of our model, as augmenting Lancaster's (1966) model of "proper" product characteristics and extending the corresponding basis for hedonic estimation.

Note 4. In fact, we expect that expertise in appraisal likely carries across all surrogate indicators, such that people who make erroneous conjectures about one $\partial z / \partial X_{k}$ will likely make larger errors about others. This is consistent with the literature, which views expertise as accruing at the level of the overall product (Alba \& Hutchinson, 1987). For the purposes of this paper, it is not necessary to introduce this complication into the modeling. However, the notion does provide motivation for thinking of expert and inexpert appraisers as constituting distinct market segments.

Note 5. Rather, that relation depends on costs and a markup resulting from a complex relationship between the heterogeneous preferences and the characteristics of competing offerings, whence the hedonic regression becomes a reduced form in which the coefficients have no obvious interpretation in terms of economic primitives. See Pakes (2003).

Note 6. For this reason, a correctly signed bias term (i.e., the same sign as $z$ when $X_{k}$ is a significant positive indicator, the opposite sign when $X_{k}$ is a significant negative indicator) is sufficient for identifying overshooting consumers, that is, the bias term need not be significantly different from zero. However, if $X_{k}$ is insignificant, the relative conjectural error of consumers is indeterminate, regardless of the sign of $X_{k}$.

Note 7. See Mast (2011).

Note 8. Our use of list prices follows other hedonic studies (e.g., Gandal, 1994; Roe, Teisl, Levy, \& Russell, 2001). The limitations of using list prices instead of actual transacted prices, which were unable to observe for this study, are discussed in Section 5.

Note 9. A distinct product consists of a specific brand with a certain number of units per package, a certain formulation (e.g., tablet, liquid-filled capsule, etc.), and a distinct set of ingredients.

Note 10. Online retailers of dietary supplements, such as Amazon and drugstore.com, and dedicated review sites, such as Buzzillions.com, invite consumers to write product reviews. Typically any visitor to the site can write one. The review process is structured to allow the consumer both to offer a written comment and a numeric rating, usually on a 5-point scale. The comment and rating are then posted to the website for other visitors to view.

Note 11 . Note that while approximately $66 \%$ of distinct products in our sample were determined to be authentic, authentic products accounted for roughly $73 \%$ of our observations. This is because authentic products were slightly oversampled across retailers relative to non-authentic products.

Note 12. See, for example, Gomstyn (2010).

Note 13. For an extended discussion, see Letizia, Greenfield, \& Reuter (2009). 